\title{
CONSULTA DE ENFERMAGEM: ESTRATÉGIA DE ABORDAGEM À GESTANTE NA PERSPECTIVA DE GÊNERO
}

\author{
Nursing appointment: a strategy of approaching to the pregnant \\ woman in the perspective of the gender
}

Consulta de Enfermería: estrategia de abordaje a la mujer embarazada en la perspectiva de género

\section{Resumo}

Relato de uma prática assistencial desenvolvida no ambulatório de um hospital geral, de caráter filantrópico, no interior do Rio Grande do Sul, no período de 1999 a 2001. Esta prática foi implementada por meio de consultas de enfermagem às mulheres gestantes, sendo subsidiada por referenciais de gênero. Ressalta-se a importância dos profissionais da saúde ampliarem a abordagem à mulher, além da gestação. E se confirma a influência dos referenciais de gênero, como um dos determinantes da condição de vida e de saúde das mulheres assistidas, apontando o pré-natal como um espaço que pode viabilizar o empoderamento e a promoção da autonomia e cidadania femininas.

Palavras-chave: Consulta de Enfermagem. Mulheres Grávidas. Gênero. Saúde da mulher.

\begin{abstract}
An assistance practice developed in the emergency department of a general hospital has been reported in the article. The general hospital is a philanthropic one, located in the interior of Rio Grande do Sul estate and this practice happened from 1999 to 2001 and wad implemented by means for nursing appointments for pregnant women. It was subsidied by references of gender. The importance of health professionals are broadering the approach for women after pregnancy was confirmed as a one of the determinat factors in life conditions and health of those assisted women, showing that the pre-birth examination is something that makes possible the empowerment and the promotion of women's autonomy and citizenship.
\end{abstract}

\section{Resumen}

Se relata una prática asistencial desarrollada en el ambulatorio de un hospital general, de caracter filantropico, en el interior de Rio Grande del Sur, en el período de 1999 a 2001. Esta práctica fue implementada por medio de consultas de enfermería a las mujeres embarazadas, siendo subsidiada por referenciales de genero. Ressaltó la importancia de que los professionales de salud amplíen el abordaje a la mujer más alla de la gestación, y confirmó la influencia de referenciales de género como uno de los determinantes de la condición de vida y de salud de las mujeres asistidas, apuntando el prenatal como un espacio que puede viabilizar el empoderamiento y la promoción de la autonomía y de la ciudadanía femeninas. 


\section{A URGÊNCIA DA TEMÁTICA GÊNERO NO CONTEXTO DA ASSISTÊNCIA À MULHER}

A sociedade determina, entre suas normas e condutas, um sistema de papéis fundamentados nas relações entre homens e mulheres, os quais não são determinados apenas pela sua biologia, mas pelo contexto político, econômico e cultural em que se encontram estabelecendo, desta forma, representações sociais do que seja masculino e feminino (Shallat ${ }^{1}$ ). Observa-se, assim, que as mulheres têm sido consideradas, ao longo dos tempos, seres incapazes e inferiores; sua participação social, muitas vezes é vista somente como procriadora, estando alicerçada em valores construídos ao longo dos séculos, representando, para muitas, fragilidade e despreparo para a vida pública.

Nas últimas décadas, entretanto, tais concepções vêm sendo superadas, tendo em vista o despertar da consciência feminina a respeito do seu potencial como ser humano que pode e deve ser sujeito de sua história. Com isso, a participação feminina vem crescendo constantemente em todos os âmbitos da sociedade, sendo considerada uma das mais importantes transformações sociais no país e no mundo (Cabral²).

Nesse contexto de mudanças, no qual os grupos organizados de mulheres tiveram participação fundamental, o Ministério da Saúde implementou, em 1984, o Programa de Assistência Integral à Saúde da Mulher - PAISM. Esse programa teve como meta $o$ atendimento global das necessidades de saúde do segmento feminino, desde a adolescência até a terceira idade. Tal iniciativa representou, na esfera das politicas públicas brasileiras, um avanço na atenção à saúde da mulher, uma vez que:

Por longos períodos, as metas governamentais sobre a saúde da mulher centraram-se na reprodução abrangendo a Saúde Materno-Infantil, onde a mulher é considerada um objeto da reproduçãa0:47

Portanto, havia uma ênfase nos aspectos biológicos da gestação, com uma abordagem eminentemente técnica que desconsiderava os inúmeros condicionantes da qualidade de vida e de saúde das mulheres.

É inegável que, o processo de Reforma Sanitária vivida no país na década de 80 foi um fator que contribuiu de forma relevante para as premissas do PAISM, uma vez que imprimiu em seu arcabouço as noções de integralidade da atenção e eqüidade. Além destas, despertou a atenção para a conquista da saúde da mulher como uma questão de direito de cidadania, vindo ao encontro da concepção de saúde assegurada na Constituição de 1988.

Nessa esteira de transformações, no nível mundial, destacam-se a Conferência Mundial de Direitos Humanos, realizada em Viena, em 1993, que reconheceu os direitos das mulheres como direitos humanos; a Conferência Internacional de População e Desenvolvimento, realizada no Cairo, em 1994, na qual a concepção de saúde reprodutiva ganhou outro enfoque, estabelecendo igualmente como prioritário os indicadores de saúde relativos à morbidade, à mortalidade e ao bem-estar geral da população feminina; e a Conferência de Pequim, em 1995, que afirmou a igualdade de direitos e oportunidades entre mulheres e homens, como condição indispensável para a justiça, a paz e o progresso em todo o mundo.

Essas premissas evidenciam a urgência em olhar a mulher para além de sua maternidade, para ampliar a concepção de saúde da mulher no âmbito dos direitos sexuais e reprodutivos, na perspectiva dos direitos humanos. Nessa corrente, além dos aspectos biológicos, a mulher deve ser percebida e abordada em sua dimensão social, econômica, histórica, política e cultural, uma vez que é na interação desses aspectos que resulta o perfil de saúde e doença do ser humano.

Inscrito nesse contexto encontra-se o gênero, entendido como a construção social do ser masculino e do ser feminino, que traz em sua essência a marca do poder, favorecendo relações desiguais entre homens e mulheres (Ministério da Saúde ${ }^{4}$ ). Esses desequilíbrios estão presentes nas leis, práticas sociais e políticas, sendo possível influenciar no aprofundamento das desigualdades existentes na sociedade e interfere de forma relevante na vida e saúde das mulheres.

Com isso é possível afirmar que, em função da organização social das relações de gênero, as mulheres estão mais vulneráveis ao sofrimento, adoecimento e morte. Dessa forma, torna-se imprescindivel:

A incorporação da perspectiva de gênero na análise do perfil epidemiológico e no planejamento de ações de saúde, que tenham como objetivo promover a melhoria das condições de vida, a igualdade e os direitos de cidadania da mulher (Ministério da Saúde ${ }^{4: 13}$ ).

Nesse sentido, as implicações para os profissionais de enfermagem são imensas, exigindo deles a busca pela compreensão do tema, bem como a forma de incorporálo no cotidiano de sua prática.

Nessa perspectiva, o presente artigo, recorte da Monografia de Especialização em Obstetrícia Tangenciando questões de gênero na abordagem à saúde da mulher: um desafio para a Enfermagem $\left(\mathrm{Cabral}^{2}\right)$, relata a prática assistencial vivenciada com mulheres gestantes que participaram de consultas de enfermagem no pré-natal no ambulatório de um hospital público do interior do Rio Grande do Sul, no período de 1999 a 2001. Esse trabalho, apoiado 
na visão de gênero, teve como objetivo assistir à mulher no ciclo gravídico-puerperal, mediante ações de educação em saúde, como forma de possibilitar a busca pela sua cidadania.

\section{GÊNERO: BREVES CONSIDERAÇÕES NA BUSCA PELA SUA COMPREENSÃO}

0 termo "gênero" foi utilizado por estudiosos estrangeiros, pela primeira vez, na década de 60 do século passado. No Brasil, a década de 80 representou um marco no início de estudos sobre a temática (Saffiotti5). Nos idos de 90, seu conceito e busca pela sua compreensão expandiu-se na academia.

As demandas por igualdade e eqüidade social, retratadas nos movimentos sociais de mulheres, têm contribuído na construção da categoria gênero como qualidade de análise das situações que marginalizam, excluem e discriminam homens e mulheres (Guzmán ${ }^{6}$ ). Nesse cenário, o conceito de gênero vem sendo utilizado de maneira contundente, opondo-se de forma radical às explicações das desigualdades sociais fundadas em características biológicas e, portanto, naturais, as quais estabeleceriam relações de dominação entre homens e mulheres e seus conseqüentes conflitos.

Para explicar a forma como as sociedades utilizam as desigualdades entre homens e mulheres como fator de organização da vida social, pesquisadores têm utilizado teorias do desenvolvimento das sociedades humanas. A orientação marxista foi uma das primeiras opções teóricas apresentadas, tendo como hipótese a subordinação da mulher como resultado do surgimento dos meios de produção(Guzmán 6 ). Tanto a origem como a manutenção da opressão da mulher em sociedades de classes acontece, graças às suas instituições: a família patriarcal monogâmica, a propriedade privada dos meios de produção e o Estado (Nascimento7).

0 feminismo liberal, ao contrário, elaborou seu pensamento a respeito da desigualdade das mulheres tendo como foco ações individuais e coletivas (Guzmán 6 ). No nível individual, responsabiliza as mulheres pela sua condição feminina e as convida a vencer a subordinação por meio do acesso ao conhecimento científico e pela obtenção de competências para integrar o mercado de trabalho. Já no Brasil, os primeiros movimentos feministas tiveram como premissa o pensamento liberal, organizando-se na busca pelo direito ao voto (Nascimento ${ }^{7}$ ). Outra corrente de pensamento - 0 radicalismo, implica em considerar a dominação masculina como universal, a qual tem sido construída por meio do patriarcado (Guzmán ${ }^{6}$ ). Reforçando tal compreensão, Johnson ${ }^{8}$ defende que uma sociedade é patriarcal na medida em que é dominada por machos, identificada com machos e centrada nos machos.
Saffiotis:17 argumenta que [...] as mulheres são objetos da satisfação sexual dos homens, reprodutoras de herdeiros, de força de trabalho e de novas reprodutoras. Em oposição aos homens, a sujeição das mulheres envolve prestação de serviços sexuais a seus dominadores, sendo ela entendida como opressão, o somatório da dominação com a exploração (Saffioti $\left.{ }^{5}\right)$. 0 patriarcado é defendido, entre outras coisas, com base na segregação ocupacional e na marginalização das mulheres e dos processos e papéis econômicos e políticos, bem como no controle de sua sexualidade e, como conseqüência, de sua capacidade reprodutiva. Neste sentido:

Seja para induzir as mulheres a ter grande número de filhos, seja para convencê-las a controlar a quantidade de nascimento, o controle está sempre em mãos masculinas, embora elementos femininos possam intermediar estes projetos $5: 18$.

Ante o conhecimento dessas vertentes, as quais tentam explicar as relações de dominação e opressão no cotidiano de mulheres e homens, é possível constatar a complexidade da temática gênero e a necessidade da sociedade, em especial das mulheres perceberem sua influência como um dos determinantes de sua vida/saúde. Por conseguinte, a prática assistencial com mulheres gestantes, objetos deste relato, procurou considerar tais referenciais como forma de subsidiar as discussões e reflexões realizadas.

\section{O CAMINHO DA PRÁTICA}

A atenção pré-natal e puerperal objetiva acolher a mulher desde o início da gravidez, assegurando, ao seu término, o nascimento de uma criança saudável e a garantia do bem-estar materno e neonatal. Para que esta atenção seja qualificada e humanizada, o Ministério da Saúde ${ }^{9}$ preconiza a incorporação de condutas acolhedoras e sem intervenções desnecessárias; e a facilidade de acesso a serviços de saúde de qualidade, com ações que integram todos os níveis da atenção: promoção, prevenção e assistência à saúde da gestante e do recém-nascido. A assistência deve ser prestada pela equipe multiprofissional de saúde, sendo que o prénatal de baixo risco pode ser inteiramente acompanhado pelo enfermeiro, segundo a Lei do Exercício Profissional de Enfermagem - Decreto n ${ }^{0}$ 94.406/87.

0 calendário de atendimento pré-natal deve ser programado em função dos períodos gestacionais que determinam maior risco materno e perinatal. Neste sentido, o Programa de Humanização no Pré-natal e Nascimento - PHPN estabelece, no mínimo, seis consultas, preferencialmente uma no primeiro trimestre, 
duas no segundo e três no último trimestre gestacional (Ministério da Saúde ${ }^{9}$ ).

Para tanto, as consultas de enfermagem no prénatal foram agendadas previamente na recepção do hospital onde se realizou a referida atividade, sendo as mulheres encaminhadas por profissionais da área da saúde. Seu desenvolvimento teve como mediadores a escuta aberta e sem julgamentos, o diálogo franco e o estímulo à reflexão, permeados por referenciais de gênero. Foram abordadas questões como direitos da mulher, principalmente sobre o respeito aos direitos sexuais e reprodutivos, seu papel na sociedade, promoção da autovalorização, auto-estima, autonomia e participação das mulheres/família na atenção à sua saúde; violência intrafamiliar; e outras questões fisiológicas e emocionais inerentes à gestação.

A gestante foi estimulada a vir acompanhada por seu companheiro ou familiar, como forma de ressaltar a importância da participação do pai na gestação e do desenvolvimento do vínculo pai-filho para o desenvolvimento saudável da criança, bem como para a inclusão do núcleo familiar no processo de gestação. Assim, em ambiente confortável e com música ambiental, a gestante/família foi acolhida. Em sua primeira consulta utilizou-se um instrumento para obter informações referentes: ao desenvolvimento gestacional; aos exames laboratoriais; sentimentos, queixas e problemas relatados pela gestante; e as orientações e encaminhamentos realizados. 0 segundo momento da consulta foi reservado para o exame físico da gestante, sendo que as orientações processaramse durante 0 seu desenvolvimento valorizando-se 0 conhecimento prévio da gestante/família, com ajustes ou negociações sempre que necessário.

\section{RELATO DAS VIVÊNCIAS COM AS MULHERES NA PERSPECTIVA DE GÊNERO}

Considerando o objetivo do trabalho, o olhar foi estendido para além daquele corpo feminino que gestava e paria buscando, acima de tudo, acolher respeitosamente cada mulher e considerando seu contexto histórico e cultural, como subsídio fundamental para a compreensão de suas queixas e necessidades, no momento da consulta. 0 compromisso com a integralidade da atenção pautou-se no acolhimento, na valorização da usuária e promoção da sua autonomia e na produção do vínculo, como estratégias para a efetivação do modelo de atenção à saúde, atualmente em construção no país.
Nessa perspectiva, as gestantes mostraram-se à vontade expressando suas dúvidas, medos e angústias, confidenciando situações íntimas. Para assegurar 0 sigilo foram utilizados pseudônimos. 0 relato de Cristal, 29 anos, primigesta, revelou dificuldades em manter relações sexuais com o marido, pois temia que o bebê se machucasse:

[...] eu ando sem vontade. Tenho vergonha dele me ver gorda desse jeito! Sempre que acontece, fico pensando que o bebê está vendo. Acho que pode machucar. E aí começa a doer. Peço para ele parar ... Mas, ele está ficando bravo. Disse que é frescura minha, que daqui a pouco não vai nem [querer] saber, vai buscar na rua o que não tem em casa ou vai me pegar à força. Tenho medo [...].

Procurou-se abordar a sexualidade como um direito de Cristal, no sentido de fornecer-lhe subsídios para que se conscientize como sujeito na relação conjugal. Entretanto, é importante ressaltar que no mundo social organizado, a partir da perspectiva dos homens, a repressão e a subjugação sexual podem ser estratégias utilizadas pelo marido de Cristal para sua dominação, de tal forma que suas necessidades biológicas, como macho, sejam prontamente satisfeitas.

Cristal revelou grande dificuldade em lidar com sua sexualidade e com os padrões de beleza física estereotipados e impostos pela sociedade consumista em que se vive. Esta situação é incentivada pela mídia, quando diariamente mostra corpos de forma cada vez mais apelativa e exagerada que, aliados à presença constante do erotismo em nosso dia-a-dia, torna 0 sexo um fácil apelo de consumo. Tal fato é evidenciado por anúncios de perfumes, roupas, jóias associado à figura de "mulher objeto sexual", cujo papel destinase a satisfazer os desejos masculinos. Em contrapartida, a publicidade de produtos de limpeza, alimentos e adornos diz respeito à figura de "mulher dona de casa" e soberana em seu lar. Assim, em qualquer dos casos - o de dona de casa e o de objeto sexual - a mulher está obedecendo a padrões estabelecidos pela sociedade, que modela estes estereótipos por meio de uma cultura de desvalorização da feminilidade e do próprio significado de ser mulher ${ }^{10}$.

Nessa perspectiva, mostrou-se para Cristal que a sexualidade vai muito além da boa forma física ou da adequação e satisfação aos padrões idealizados de beleza. Por essa razão, a sexualidade deve ser entendida como forma de relações estabelecidas com o mundo e com a vida, devendo ser vivenciada como 
prazer e não como obrigação. Sugeriu-se que Cristal conversasse com o marido sobre suas angústias e que, juntos, buscassem formas alternativas de sentir e dar prazer, uma vez que a relação sexual pode e deve acontecer junto à maternidade, não havendo possibilidade de machucar o bebê durante a sua realização.

Em meio às conversas que se processaram nas consultas, percebeu-se que o foco central para muitas mulheres foi a própria gestação, na qual a maternidade constituiu-se como razão única da sua existência, visto que seu objetivo de vida era percebido como "servir ao marido e criar os filhos", reproduzindo os tradicionais papéis da família patriarcal. Essa constatação é evidenciada pelo relato de Rubi, quando ela diz:

[...] eu acho importante a mulher estudar e trabalhar, ser dona da sua vida. Mas, lá em casa não adianta ... Da última vez que tentei sair para trabalhar, ele me incomodou tanto, que tive que largar o emprego ... Uma vez, até tentei largar dele, mas ele foi atrás e disse que, se não voltasse pra casa, acabava comigo. E depois se eu o largasse de verdade, o que seria de mim e das crianças? Trabalho está difícil ... Então, é melhor esquecer, e nem pensar [...].

A falta de autonomia e independência financeira de Rubi denuncia a realidade de muitas mulheres que, pela falta de perspectiva de uma formação profissional que lhes dê condições de ser sujeito de sua vida, entregam-se aos cuidados da casa e dos filhos como condição inexorável. De fato, muitas mulheres vivem em um sistema de gênero tão opressor, que não conseguem desenvolver a autoconfiança necessária para levar sua vida autonomamente. Por essa razão, a vivência da sua feminilidade ainda é caracterizada pelo silenciar-se e conformar-se com a sua situação.

Deste modo, ao submeter-se às estratégias de controle do marido, Rubi reforça e sustenta o estereótipo de esposa ideal e "rainha do lar", cujas funções assumidas pelo cuidado e educação dos filhos e demais funções domésticas the conferem um pequeno papel de destaque frente ao marido. Acreditase que a inclusão destas mulheres num sistema educacional voltado para a qualificação profissional deverá proporcionar condições para que rompam com o estigma de segregação social, econômica e cultural. Em conseqüência, altera-se a organização de sua vida familiar, o que the possibilita mais autonomia/cidadania e resgate da auto-estima.

Somando-se a este pensamento, destaca-se que, a partir das relações de gênero, firmadas no contexto social, também se estabelece o ideário de sua representação, ou seja, o entendimento que a sociedade tem daquilo que é feminino/masculino. Por meio de suas normas, fica estabelecido como se deve pensar, agir, vestir, enfim, o lugar de cada um neste cenário. Entretanto, a estereotipia destes papéis de gênero e as imagens contraditórias referidas ao seu desempenho e auto-estima funcionam como máscaras. Logo, os homens devem vestir a máscara de macho, da mesma forma que as mulheres devem vestir a máscara de submissas, sendo que o uso de tais máscaras significa a repressão de todos os desejos de caminharem em outra direção ${ }^{10}$.

Essas percepções possibilitaram abordar referenciais de gênero com a mulher e seu acompanhante, como forma de possibilitar a valorização quanto ao papel da mulher na sociedade. Para tanto, enfatizou-se a importância do cultivo da auto-estima, da auto-valorização e da autonomia, condições fundamentais para a busca da cidadania feminina.

Ao intermediar o diálogo sobre referenciais de gênero, evidenciou-se manifestações de que a ideologia machista que considera o homem um ser superior à mulher não está presente somente no pensamento masculino. Ao contrário, as próprias mulheres acreditam que são incapazes de usar a razão assim como, de lutar contra ocorrências adversas transmitindo estas idéias a seus filhos, que as perpetuam.

Para evitar o risco de não encarnar adequadamente o papel de macho, o homem deve inibir sua sensibilidade e castrar certas qualidades, por serem consideradas femininas. Assim, para sustentar um sistema de gênero androcêntrico, Saffioti ${ }^{10: 25}$ comenta que:

[...] o homem será considerado macho na medida em que for capaz de disfarçar, inibir, sufocar seus sentimentos. A educação de um verdadeiro macho inclui necessariamente, a famosa ordem: Homem (com H maiúsculo) não chora. Quantos homens tiveram que engolir lágrimas diante da tristeza, da angústia, do luto, em nome desta norma de conduta!

Esta compreensão tem integrado o pensamento de uma sociedade que desumaniza e que proíbe o homem de expressar seus sentimentos. Nessa perspectiva, a exigência social da negação do "feminino" como parte integrante de si apresenta-se como uma das manifestações mais importantes do patriarcado, reforçada pela socialização de meninos que, desde cedo, são educados para responder aos padrões sociais de masculinidade e reprimir suas emoções, sensibilidade, afetividade, fraqueza e/ou insegurança, visto que tais sentimentos dizem respeito "exclusivamente" ao universo feminino. 
É necessário a ampliação do "conceito de feminino", para que os homens sintam-se nele incluídos decidindo-se por mudanças de atitudes e adoção de comportamentos menos competitivos e mais cooperativos, menos subordináveis e mais igualitários ${ }^{11}$. Acredita-se que a luta das mulheres não diz respeito apenas a elas, mas também aos homens, razão pela qual seria impossível mudar comportamentos femininos sem redefinir também os papéis masculinos.

Algumas falas das mulheres assistidas, no entanto, fazem emergir um contexto que promete um outro pensar e sentir a masculinidade. É o caso de Granada, quando fala que:

[...] Meu marido já é diferente: me ajuda em casa, olha novela comigo, é sensível, carinhoso, super-romântico e se emociona bem fácil. Os amigos dele 0 apelidaram de chorinho e um vizinho fica dizendo que esse jeito dele é coisa de marica. Mas não tem nada a ver! A minha sogra ficou viúva com seis filhos para criar, e eles tinham que ajudar no serviço de casa. Acho que está certo, porque hoje ele me ajuda em tudo e para quem duvida ele é muito macho!

0 relato evidencia 0 significativo papel da família na socialização primária que se efetiva no interior dos lares, quando se estabelecem as primeiras noções sobre gênero, com suas representações sociais estabelecidas desde o nascimento, ocasião em que 0 recém-nascido passará a receber um tratamento específico de menino ou menina.

Desse modo, quando as mães proíbem os filhos de chorar, alegando que homem não chora e exigem que as filhas sintam-se como mocinhas, estão passando este sistema de idéias que privilegia o masculino em prejuízo do feminino. Para tanto, no processo de conscientização dessas mulheres, procurou-se enfatizar a importância de uma educação voltada para 0 respeito às diferenças.

Considerando a cultura patriarcal e o exercício da masculinidade, com base em parâmetros competitivos, a sociedade determina que homens devem ser viris, conquistadores, fortes e corajosos para exercer 0 poder e obter o sucesso. Conseqüentemente, a raiva, a agressividade, a violência e seus recorrentes mecanismos de brutalidade são considerados como manifestações tipicamente masculinas para a resolução de conflitos, numa sociedade historicamente machista. No entanto, o fato dos homens também serem prejudicados no sistema patriarcal não significa que eles sejam oprimidos por outros homens, da mesma forma que as mulheres 0 são.

\section{CONSIDERAÇÕES FINAIS}

$\mathrm{Na}$ interação com as mulheres no ciclo gravídicopuerperal percebeu-se uma grande influência da cultura machista sobre suas personalidades, atitudes, hábitos e comportamentos, permitindo compreender que os cuidados com sua saúde também se apresentam permeados pelas questões de gênero, refletindo os laços estruturais entre o corpo feminino e sua representação na sociedade.

Observou-se também, que o papel de subordinação da mulher na família ainda reproduz a estrutura do poder patriarcal, por meio de mecanismos ideológicos e culturais, constituindo-se num importante fator para produzir indivíduos submissos. Dessa forma, espera-se que desde cedo a mulher seja educada dentro dos valores sociais esperados para desempenhar os papéis considerados essencialmente femininos, em especial o da maternidade.

Com este estudo, percebeu-se que, embora a mulher encontre-se voltada para a maternidade, é possível, sim, abordar questões de gênero trazendoas para a roda de discussão.

Nesse contexto, reafirma-se o compromisso com a saúde da mulher envolvendo aspectos sociais e culturais na promoção da sua autonomia/cidadania, bem como a construção de espaços que viabilizem o empoderamento dessas mulheres, para que elas atuem como agentes de transformação da sua realidade social.

Dessa experiência emergiu a compreensão da importância dos profissionais da saúde ampliarem a abordagem à mulher além da gestação. Ressaltou-se também a influência dos referenciais de gênero, como um dos determinantes da condição de vida das mulheres assistidas.

Deste modo, embora sendo um desafio, é papel do enfermeiro olhar mais longe e ver a mulher que existe em cada gestante procurando alongar sua visão a respeito das questões, que poderão possibilitar seu crescimento como ser humano e cidadã e fortalecer a importância da inclusão de referenciais de gênero e cidadania na prática da enfermagem. 


\section{Referências}

1. Shallat L. Conceitos de gênero no planejamento do desenvolvimento: uma abordagem básica. Brasilia (DF): Conselho dos Direitos da Mulher; 1995.

2. Cabral FB. Tangenciando questões de gênero na abordagem à saúde da mulher: um desafio para a enfermagem. [monografia do Curso de Especialização em Enfermagem Obstétrica]. Santa Maria (RS): UFSM; 2002

3. Tyrrel MAR, Santos FRP. Assistência à mulher no pré-parto e parto na perspectiva da maternidade segura. Rev Esc Enferm Anna Nery, 2005 abr; 9 (1): 46-53.

4. Ministério da Saúde (BR) Secretaria Especial de Políticas para as Mulheres. Plano Nacional de Políticas para as Mulheres. Brasilia (DF); 2004.

5. Saffiotti HIB. 0 estatuto teórico da violência de gênero. São Paulo (SP); 1997 (cópia xerox do documento).

6. Guzmán YER. Violência conjugal contra a mulher: bases para o aconselhamento em enfermagem. [tese de doutorado] Rio de Janeiro (RJ): Escola de Enfermagem Ana Nery /UFRJ; 2003.

7. Nascimento E. Assistência de enfermagem na perspectiva de gênero: concepções de mulheres em um centro de saúde-Salvador (BH). [tese de doutorado] Rio de Janeiro (RJ); Escola de Enfermagem Ana Nery /UFRJ; 2000.

8. Johnson Allan G. Dicionário de Sociologia. Guia prático da linguagem sociológica. Rio de Janeiro (RJ): Jorge Zahar ; 1997.

9. Ministério da Saúde (BR).Secretaria de Atenção a Saúde. Departamento de Ações Programáticas Estratégicas. Área Técnica de Saúde da Mulher. Pré-natal e Puerpério: atenção qualificada e humanizada. Série A . Normas e Manuais Técnicos n 5. Brasília (DF); 2005.

10. Saffioti HIB. 0 poder do macho. São Paulo (SP): Moderna; 1987.

11. Muraro RM, Boff L. Feminino e masculino: uma nova consciência para 0 encontro das diferenças. $3^{\text {a }}$ ed. Rio de Janeiro (RJ): Sextante; 2002.

\section{Sobre as Autoras}

Fernanda Beheregaray Cabral

Enfermeira Especialista em Enfermagem Obstétrica. Mestranda do Programa de Pós-Graduação Mestrado em Enfermagem da Universidade Federal do Rio Grande do Sul UFRGS. Docente do Curso de Graduação em Enfermagem da Universidade Regional Integrada URI Santiago/RS. E-mail: fb.cabral@terra.com.br

\section{Lúcia Beatriz Ressel}

Doutora em Enfermagem. Docente do Departamento de Enfermagem da Universidade Federal de Santa Maria - UFSM. Membro do Grupo de Pesquisa Cuidado, Saúde e Enfermagem.

\section{Maria Celeste Landerdahl}

Enfermeira, Mestre em Assistência de Enfermagem. Docente do Departamento de Enfermagem da Universidade Federal de Santa Maria - UFSM. Membro do Grupo de Estudos e Pesquisas em Enfermagem e Saúde - GEPES. 